\title{
CULTIVO DE BACTÉRIAS UTILIZANDO GLICERINA RESIDUAL PARA OBTENÇÃO DE EXOPOLISSACARÍDEOS
}

\author{
V.A. RIBEIRO ${ }^{1}$, M. TEIXEIRA ${ }^{1}$, C. A. V. BURKERT ${ }^{1}$ \\ ${ }^{1}$ FURG, Universidade Federal do Rio Grande, Escola de Química e Alimentos \\ email: vanessa.amaralribeiro@gmail.com
}

\begin{abstract}
RESUMO - Os exopolissacarídeos bacterianos (EPSs) são amplamente utilizados no setor industrial como agentes gelificantes, podendo ser sintetizados por bactérias como Rhizobium e Mesorhizobium. Assim, o presente trabalho teve como objetivo avaliar a produção de EPSs por diferentes bactérias do gênero Rhizobium e Mesorhizobium usando glicerina residual como fonte de carbono. Foram testadas 4 diferentes espécies de bactérias: Rhizobium leguminosarum bv vicae Semia 344, Rhizobium tropici Semia 4077, Mesorhizobium loti Semia 816 e Mesorhizobium huakuiu Semia 4779. Os cultivos foram realizados em triplicata em frascos agitados a $30^{\circ} \mathrm{C}$ e $200 \mathrm{rpm}$ utilizando meio de cultivo contendo glicerina residual, $\mathrm{KH}_{2} \mathrm{PO}_{4}, \mathrm{~K}_{2} \mathrm{HPO}_{4}, \mathrm{MgSO}_{4} .7 \mathrm{H}_{2} \mathrm{O}, \mathrm{NaCl}$, extrato de levedura, $\mathrm{MnCl}_{2} .4 \mathrm{H}_{2} \mathrm{O}$ e $\mathrm{CaCl}_{2} .2 \mathrm{H}_{2} \mathrm{O}$, sendo o $\mathrm{pH}$ ajustado para 7,0 acompanhando-se biomassa, $\mathrm{pH}$ e, ao término dos cultivos, a concentração de EPSs. A bactéria Mesorhizobium loti Semia 816 mostrou-se promissora para produção de EPSs, atingindo, em 96 h, biomassa, $\mathrm{pH}$ e concentração de EPSs de 2,39 $\pm 0,05 \mathrm{~g} / \mathrm{L}$, $5,27 \pm 0,01$ e 4,90 $\pm 0,2$, respectivamente. Quanto à viscosidade, foi observado um comportamento pesudoplástico, com maior valor para a viscosidade inicial sendo observado para a bactéria Rhizobium tropici Semia 4077 ( $358 \mathrm{mPas}$ em uma solução $5 \% \mathrm{~m} / \mathrm{v}$ ).
\end{abstract}

\section{INTRODUÇÃO}

Os exopolissacarídeos microbianos (EPSs), também conhecidos como gomas, são polissacarídeos extracelulares produzidos por micro-organismos e possuem a capacidade de formar géis e soluções viscosas em meio aquoso (Monteiro et al., 2012). Essas gomas são amplamente utilizadas na indústria de alimentos como espessantes, estabilizantes e agentes gelificantes devido à estabilidade de seus géis em meio aquoso (Donot et al., 2012).

Nos últimos anos, diversos micro-organismos produtores de exopolissacarídeos tem sido investigados. Dentre eles, as bactérias diazotróficas tem se destacado por produzirem quantidades consideráveis de exopolissacarídeos, como as do gêneros Rhizobium, Mesorhizobium e Brazyrhizobium (Monteiro et al., 2012; Staudt et al., 2012 ; Castellane e Lemos, 2007). Na maioria das vezes, os EPSs rizobianos produzidos são heteropolissacarídeos, compostos de diferentes tipos de monossacarídeos (Becker e Pühler, 1998 ; Castellane e Lemos, 2007). As bactérias diazotróficas são responsáveis pela fixação do nitrogênio molecular atmosférico $\left(\mathrm{N}_{2}\right)$ em íon amônio $\left(\mathrm{NH}_{4}{ }^{+}\right)$, sendo 
usado para a fixação do nitrogênio nas raízes de plantas leguminosas, processo que facilita a obtenção de nutrientes e fornece proteção ao ambiente (Monteiro et al., 2012).

A produção de EPS é influenciada principalmente pelas condições do meio de cultivo, sendo a fonte de carbono um importante fator de influencia no processo de biossíntese de EPS (Ruas-Madiedo e de Los Reyes, 2005; Gharzouli et al., 2012). Neste contexto, o presente trabalho teve como principal objetivo estudar o cultivo de diferentes bactérias diazotróficas dos gêneros Rhizobium e Mesorhizobium quanto à produção de EPSs usando a glicerina residual como principal fonte de carbono. Cabe salientar que são escassos estudos abordando a produção EPSs por bactérias diazotróficas com esta fonte de carbono.

\section{MATERIAL E MÈTODOS}

Neste estudo, foram testadas 4 diferentes bactérias: Rhizobium leguminosarum bv vicae SEMIA 344, Rhizobium tropici SEMIA 4077, Mesorhizobium loti SEMIA 816 e Mesorhizobium huakuiu SEMIA 4779, cedida pela FEPAGRO (Fundação Estadual de Pesquisa Agropecuária).

Como fonte de carbono foi utilizada a glicerina residual proveniente da síntese do biodiesel, fornecido pela empresa BS Bios Indústria e Comércio de Biodiesel Sul Brasil S/A, localizada em Passo Fundo - RS.

Para o preparo do inóculo, foi usado 1 tubo de cultura microbiana reativada, sendo raspadas com $10 \mathrm{~mL}$ de água peptonada $0,1 \%$ e transferida para cada Erlenmeyer de $500 \mathrm{~mL}$ contendo $100 \mathrm{~mL}$ de meio YMA (yeast manitol), ajustado a $\mathrm{pH} \mathrm{7,0,}$ conforme proposto por Dutra et al. (2004), sendo utilizado a glicerina residual como fonte de carbono. A suspensão foi incubada a $30^{\circ} \mathrm{C} \mathrm{em}$ frascos agitados a $200 \mathrm{rpm}$ e foi realizado o acompanhando do crescimento celular por densidade óptica (DO) a $600 \mathrm{~nm}$.

Os cultivos foram realizados em frascos Erlenmeyers de $500 \mathrm{~mL}$ com volume inicial de $100 \mathrm{~mL}$, resultante da adição do meio de cultivo e suspensão de bacteriana. $\mathrm{O}$ meio de cultivo foi preparado na forma concentrada a fim de resultar na seguinte composição $(\mathrm{g} / \mathrm{L})$ proposta por Dutra et al. (2004) com modificações: 10 glicerina residual; $0,4 \quad \mathrm{KH}_{2} \mathrm{PO}_{4} ; 0,1 \quad \mathrm{~K}_{2} \mathrm{HPO}_{4} ; 0,2 \quad \mathrm{MgSO}_{4} .7 \mathrm{H}_{2} \mathrm{O} ; 0,1 \mathrm{NaCl} ; 0,4$ extrato de leveduras; $0,12 \mathrm{MnCl}_{2} 4 \mathrm{H}_{2} \mathrm{O} ; 0,15 \mathrm{CaCl}_{2}$. $2 \mathrm{H}_{2} \mathrm{O}$, pH ajustado em 7,0.

As amostras foram retiradas a cada $24 \mathrm{~h}$ e centrifugadas a $5000 \mathrm{x}$ g por $30 \mathrm{~min}$. No sobrenadante foi determinado o $\mathrm{pH}$ e foi adicionado álcool etílico $96 \%$ na proporção de 1:3 para precipitação da goma. Essa suspensão foi armazenada sob refrigeração a \pm $4^{\circ} \mathrm{C}$ durante $24 \mathrm{~h}$. Após a suspensão foi centrifugada a $5000 \mathrm{x} \mathrm{g} \mathrm{a} 4^{\circ} \mathrm{C}$ por 15 minutos, sendo filtrada à vácuo para recuperação do exopolissacarídeo. $\mathrm{O}$ precipitado foi colocado em placas de Petri previamente pesadas e secando-se em estufa $\left(45^{\circ} \mathrm{C}\right)$ por 24 $\mathrm{h}$ até a massa constante.

Já a sedimento foi lavado, novamente centrifugado a 5000 x g por 15 min e então ressuspendido em volume apropriado, para determinação da concentração de biomassa por densidade óptica a $600 \mathrm{~nm}$ em espectrofotômetro, convertendo-se em g/L a partir de uma curva padrão de biomassa para cada micro-organismo, conforme descrito por Messomo (2007).

A analise da viscosidade da solução aquosa dos ESPs produzido a $5 \%(\mathrm{~m} / \mathrm{v})$ foi realizada em um viscosímetro rotacional Brookfield modelo DV- III Ultra, com spindle 51 a $25^{\circ} \mathrm{C}$. 


\section{RESULTADOS E DISCUSSÕES}

As variações da concentração de biomassa e do pH em relação ao tempo foram mostrada na Figura 1.
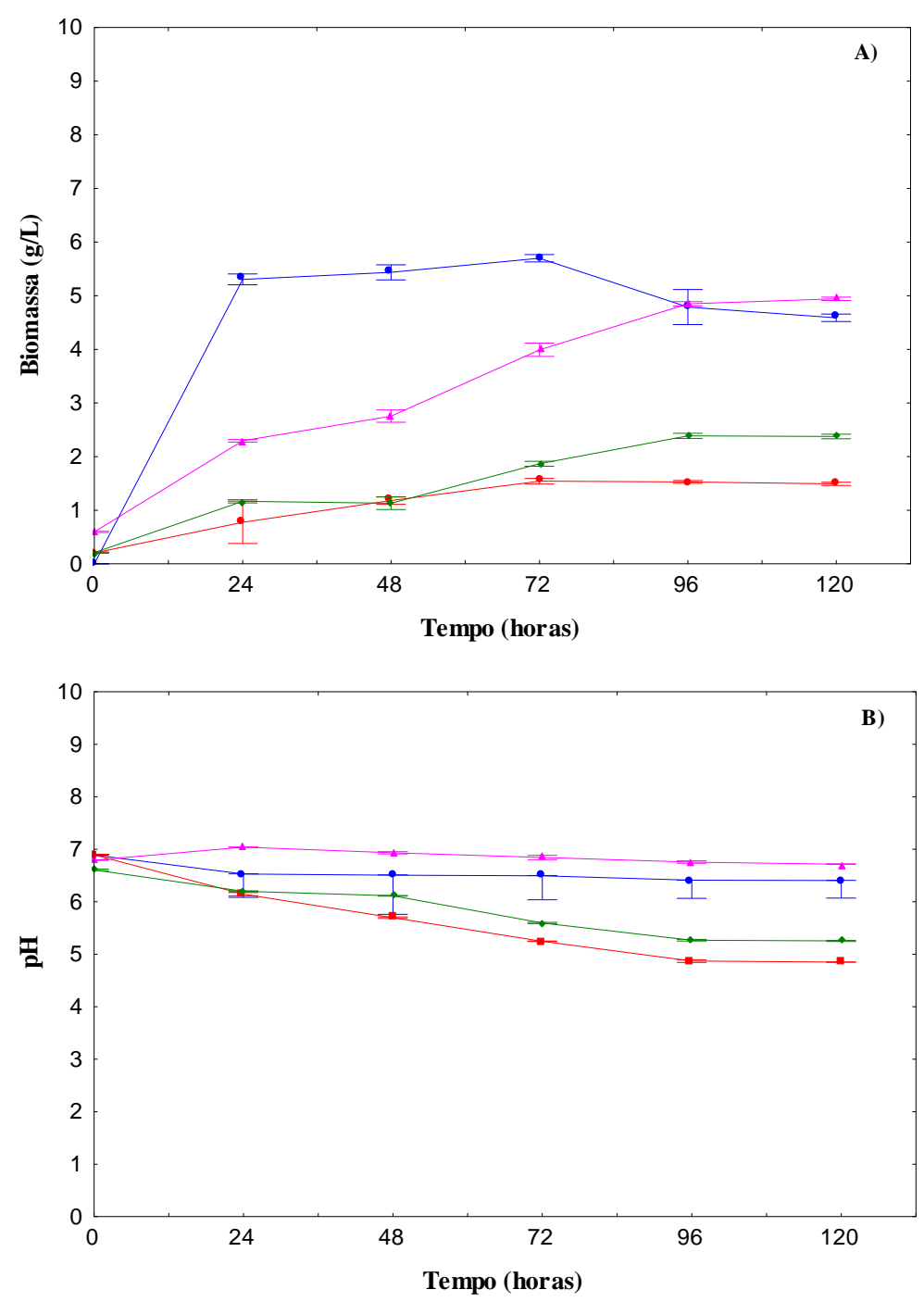

Figura 1- Concentração de biomassa (A) e pH (B) para as diferentes bactérias cultivadas em meio contendo glicerina residual. 호 소 Rhizobium tropici Semia 4077, 호 leguminosarum bv viciae Semia 344, 푸 Mesorhizobium loti Semia 816, 두 Mesorhizobium huakuiu Semia 4779.

As bacterias Rhizobium tropici Semia 4077 e Rhizobium leguminosarum bv viciae Semia 344, atingiram a concentração máxima de biomassa em 72h, respectivamente, 5,70 $\pm 0,07$ e 1,54 \pm 0,05 g/L. Já os micro-organismos Mesorhizobium loti Semia 816 e Mesorhizobium huakuiu Semia 4779 alcançaram a concentração celular máxima em 96 e $120 \mathrm{~h}$ de cultivo, de 2,39 $\pm 0,05$ e 4,94 \pm 0,03 g/L respectivamente. Quanto ao $\mathrm{pH}$, a variação mais pronunciada foi observada para as 
bactérias Rhizobium leguminosarum bv viciae Semia 344 e Mesorhizobium loti Semia 816, atingindo, respectivamente, 4,85 e 4,93 (Figura 1B). Segudo Messomo (2007), a produção de EPSs não possui uma relação direta com o crescimento celular.

As concentrações de EPSs produzidos pelos micro-organismos estudados estão indicadas na Figura 2. As bactérias Rhizobium tropici Semia 4077 e Rhizobium leguminosarum bv viciae Semia 344 alcançaram a produção de EPSs máxima em 48 horas de cultivo, respectivamente $0,75 \pm 0,00$ e 2,32 $\pm 0,44 \mathrm{~g} / \mathrm{L}$, enquanto os Mesorhizobium loti Semia 816 e Mesorhizobium huakuiu Semia 4779 a sua produção máxima de EPSs foi atingida em 96 horas de cultivo, com os valores de 4,90 \pm 0,21 e $1,75 \pm 0,13 \mathrm{~g} / \mathrm{L}$, respectivamente.

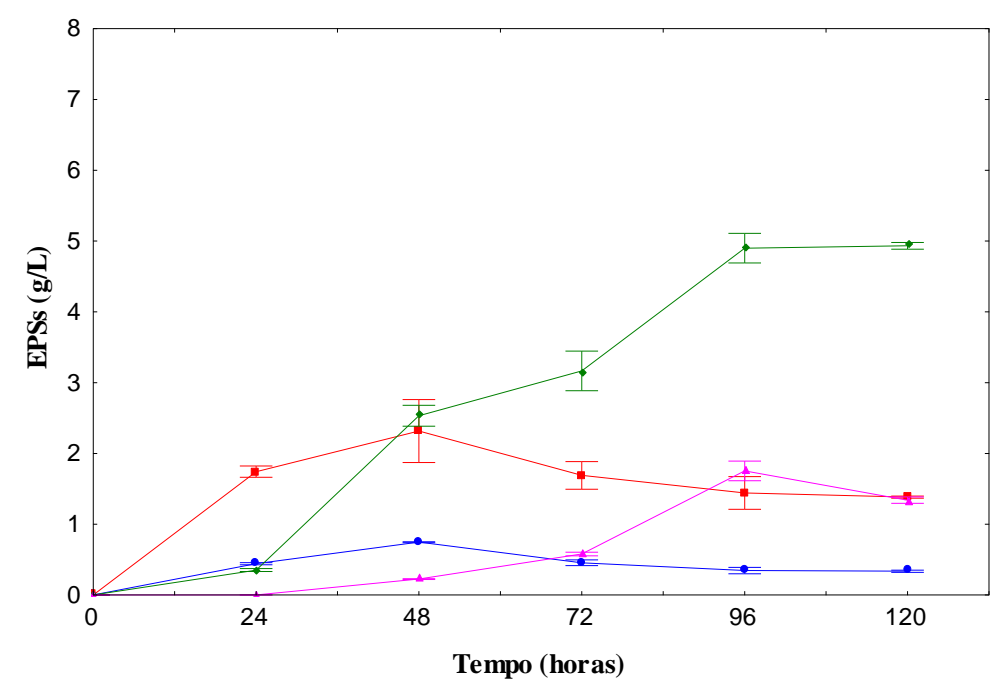

Figura 2- Produção de EPSs para as diferentes bactérias cultivadas em meio contendo glicerina residual. 코 Rhizobium tropici Semia 4077, 호 viciae Semia 344, 코 Mesorhizobium loti Semia 816, 구 Mesorhizobium huakuiu Semia 4779.

Staudt et al. (2012) obteve uma produção de EPSs 4,08 g.L - $^{-1}$ utilizando sacarose $(10 \mathrm{~g} / \mathrm{L})$ como fonte de carbono no cultivo de Rhizobium tropici CIAT 899 seguindo uma relação de $\mathrm{C} / \mathrm{N}$ de 20, enquanto Ghosh et al. (2005), em cultivo do Rhizobium sp. CIAT899 em um meio contendo $20 \mathrm{~g} / \mathrm{L}$ de manitol atingiu uma produção de $1,89 \mathrm{~g} / \mathrm{L}$ de EPSs com relação C/N de 20. Mandal et al.(2007) produziu 0,35 g/L de EPSs em um meio contendo $10 \mathrm{~g} / \mathrm{L}$ de manitol adicionado com $3 \mathrm{~g} / \mathrm{L}$ de asparagina no cultivo da Rhizobium sp. VMA301 com relação C/N de 3,3.

Kumari et al. (2009) estudou diferentes cepas da espécie Indigofera viscosa, obtendo uma concentração de EPS de $0,876 \mathrm{mg} / \mathrm{g}$ usando a glicerina como sua principal fonte de carbono.

Com os EPSs obtidos nos tempos de cultivo correspondentes à produção máxima, foi determinada a viscosidade de soluções aquosas a $5 \% \mathrm{~m} / \mathrm{v}$, conforme mostra a Figura 3. 


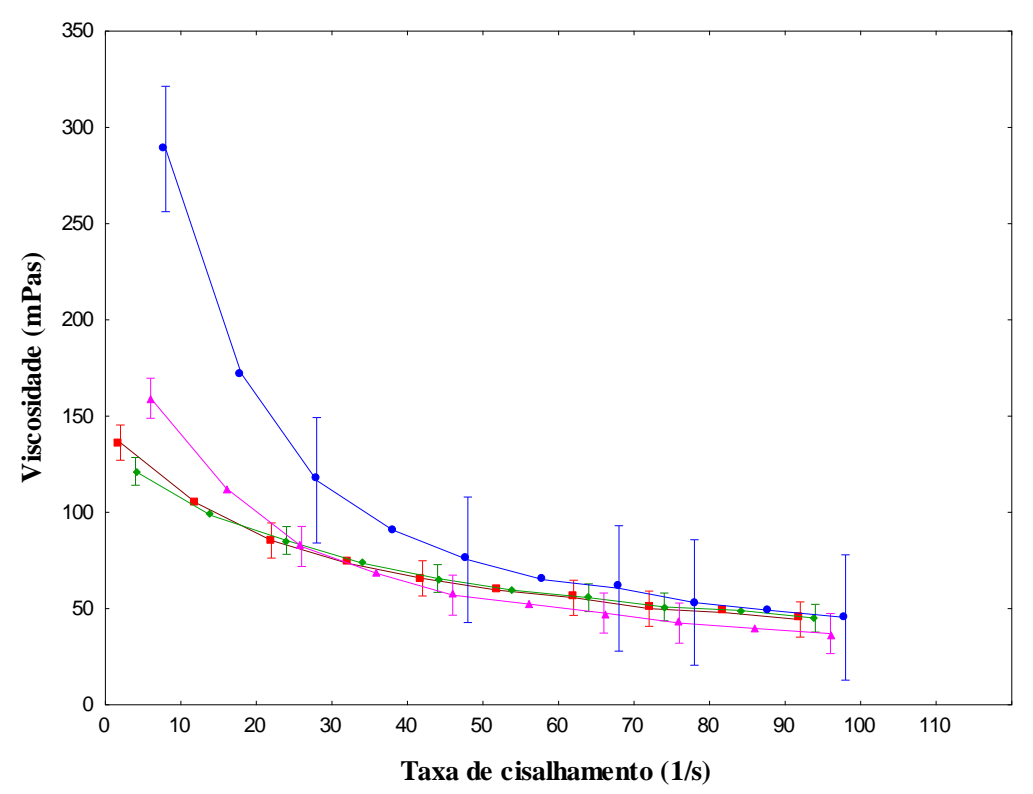

Figura 3 - Variação da viscosidade aparente em função da taxa de cisalhamento, em soluções aquosas de exopolissacarídeo $(5 \% \mathrm{p} / \mathrm{v})$ produzidos bactérias cultivadas em meio contendo glicerina residual. 호 호 Rhizobium tropici Semia 4077, 코 bv viciae Semia 344, ambos em $48 \mathrm{~h}$ de cultivo, 코 Mesorhizobium loti Semia 816, Thesorhizobium huakuiu Semia 4779 ambos em 96 h de cultivo.

De acordo com Figura 3, foi observado que as quatros soluções de EPSs produzidos pelos micro-organismos testado apresentaram comportamento não newtoniano, pseudoplástico. Um comportamento não newtoniano de fluido se caracteriza pela variação da viscosidade em função da taxa de cisalhamento e os fluidos pseudoplásticos são não newtoniano, em que o aumento da taxa de cisalhamento resulta em decréscimo da viscosidade (Fernandes et al., 2010). Essa característica reológica pseudoplástica tem sido observada por inúmeros autores no estudo de EPSs produzidos por Rhizobium sp (Kaci et al., 2005; Barreto, 2011; Aranda-Selverio et al., 2010; Fernandes et al., 2010) e em bactérias do gênero Xanthomonas (Rottava et al., 2009). As bactérias Rhizobium leguminosarum bv viciae Semia 344, Mesorhizobium loti Semia 816, Mesorhizobium huakuiu Semia 4779 apresentaram viscosidades semelhantes, porem diferente das Rhizobium tropici Semia 4077, indicando que essa solução aquosa apresentam menor resistência de escoamento. Almeida et al. (2009) encontrou uma viscosidade entorno de $150 \mathrm{mPas}$ em solução aquosa $5 \%(\mathrm{~m} / \mathrm{v})$ do EPSs produzido por Rhizobium sp Isolado 53.5.

\section{CONCLUSÕES}

As bactérias diazotróficas testadas foram capazes de produzir EPSs a partir da glicerina residual como fonte de carbono no meio de cultivo destacando a Mesorhizobium loti Semia 816, com produção de 4,90 $\pm 0,2 \mathrm{~g} / \mathrm{L}$. Todos os EPSs produzidos apresentaram comportamento pseudoplástico em soluções aquosas de $5 \%$ $\mathrm{m} / \mathrm{v}$, com maior valor de viscosidade inicial (358 mPas) observado para a Rhizobium tropici Semia 4077. 


\title{
5. AGRADECIMENTOS
}

\author{
CNPq, FAPERGS e FEPAGRO
}

\section{REFERÊNCIA}

ALMEIDA, J.P.S.; FERNANDES JÚNIOR, P.I., XAVIER, G.R.; RUNJANEK, N.G.; OLIVEIRA, P.J. Preparação e caracterização de exopolissacarídeos por síntese bactérias do gênero Rhizobium e sua aplicação como veículo de inoculação. Anais do VIII Congresso Brasileiro de Engenharia Química, 2009.

ARANDA-SELVERIO, G.; PENNA, A.L.B.; CAMPOS-SÁS, L.F.; SANTOS JÚNIOR, O.; VASCONCELOS, A.F.D.; SILVA, M. de L.C. da; LEMOS, E.G.M.; CAPANHARO, J.C.; SILVEIRA, J.L.M.S. Propriedades reológicas e efeito da adição de sal na viscosidade de exopolissacarídeos produzidos por bactérias do gênero Rhizobium. Química Nova, v. 33, p. 895-899, 2010.

BARRETO, M.C.S.; FIGUEIREDO, M.V.B.; BURITY, H.A. ; SILVA, M.L.R.B.; LIMA-FILHO, J.L. Produção e comportamento reológico de biopolímeros produzidos por rizóbios e caracterização genética. Revista Brasileira Agrociência, v. 17, p. 221-227, 2011.

BECKER, A.; PÜHLER, A. Production of exopolysaccharides. In: SPAINK, H.P.; KONDOROSI, A.; HOOYKAAS, J.J. (Ed.). The Rhizobiaceae. Dordrecht: Kluwer Academic Publishers, p. 97-118, 1998.

CASTELlANE, T.C.L. e LEMOS E.G.M. Composição de exopolissacarídeos produzidos por estirpes de rizóbios cultivados em diferentes fontes de carbono. Pesquisa Agropecuária Brasileira, v. 42, p.1503-1506, 2007.

DONOT, F.; FONTANA, A.; BACCOU, J.C. GALINDO, S.S. Microbial exopolysaccharides: Main examples of synthesis, excretion, genetics and extraction. Carbohydrate Polymers, v. 87, p. 951- 962, 2012.

DUTRA, F.P; DA COSTA, A. C.A.; LOPES, L. M. A.; BARROS, A.; SÉRVULO, E.F. C.; FRANÇA, F. P. Effect of Process Parameters on Production of a Biopolymer by Rhizobium sp. Applied Biochemistry and Biotechnology, v. 114, p. 639-652, 2004.

FERNANDES JÚNIOR P.I.; ALMEIDA, J.P.S.; PASSOS, S. R. OLIVEIRA, P.J.; RUMJANEK, N.G. E XAVIER, G.R. Produção e comportamento reológico de exopolissacarídeo sintetizados por rizóbios isolados de guandu, Pesquisa Agropecuária. Brasileira, v.45, p.1465-1471, 2010. 
GHARZOULI R.; BENAHMED A.; BENHIZIA Y.; BENGUEDOUAR, A. Influence of carbon source on the production of exopolysacharides by Rhizobium sullae and on the nodulation of Hedysarum coronarium L. legume. African Journal of Microbiology Research, v. 6, p. 5940-5946, 2012.

GHOSH A. C.; GHOSH S.; BASU, P. S. Production of extracellular polysaccharide by a Rhizobium species from root nodules of the leguminous tree Dalbergia lanceolaria. Engineering Life Sciences, v. 5, p. 378-382, 2005.

KACI, Y.; HEYRAUD, A.; BARAKAT, M.; HEULIN, T. Isolation and identification of an EPS-producing Rhizobium strain from and soil (Algeria): characterization of its EPS and the effect of inoculation on wheat rhizosphere soil structure. Research in Microbiology, v. 156, p. 522-531, 2005.

KUMARI, B. S; RAM, M.R.; MALLAIAH, K.V. Studies on exopolysaccharide and indole acetic acid production by Rhizobium strains from Indigofera. African Journal of Microbiology Research, v. 3, p. 010-014, 2009.

MANDAL, S., RAY, B.; DEY, S.; PATI B. Production and composition of extracellular polysaccharide synthesized by a Rhizobium isolate of Vigna mungo (L) Hepper. Biotechnology Letter , v. 29, p. 1271-1275, 2007.

MESOMO,M. C. Produção de goma xantana em biorreator utilizando meio a base de soro de queijo. Dissertação de Mestrado do Programa de Pós-Graduação em Engenharia de Alimentos. Centro Tecnológico de Uri. Campus de Erechim, Rio Grande do Sul. Erechim, 2007.

MONTEIRO, N. K.; ARANDA-SELVERINO, G.; EXPOSTI, D. T. D.; SILVA, M.L. C.; LEMOS, E.G.M.; CAMPANHARO, J.C.; SILVEIRA, J.L.M. Caracterização química dos géis produzidos pelas bactérias diazotróficas Rhizobium tropici e Mesorhizobium sp. Química Nova, v. 35, p. 705-708, 2012.

ROTTAVA, I.; BATESINI, G.; SILVA, M.F.; LERIN, L.; OLIVEIRA, D.; PADILHA, F.F.; TONIAZZO, G.; MOSSI, A.; CANSIAN, R.L.; DI LUCCIO, M.; TREICHEL, H. Xanthan gum production and rheological behavior using different strains of Xanthomonas sp. Carbohydrate Polymers, v. 77, p. 65-71, 2009.

RUAS-MADIEDO, P.; DE LOS REYES-GAVILÁN, C.G. Invited Review: Methods for the Screening, Isolation and Characterization of Exopolysaccharides produced by lactic acid bacteria. Journal Dairy Science, v. 88, p. 843-856, 2005.

STAUDT , A.K.; WOLFE, L.G., SHROUT, J.D. Variations in exopolysaccharide production by Rhizobium tropici. Archives of Microbiology, v. 194, p. 197-206, 2012. 